Izumi, Volume 5, No 2, 2016

e-ISSN: 2502-3535, p-ISSN: 2338-249X

Tersedia online di http://ejournal.undip.ac.id/index.php/izumi

\title{
ANALISIS KESALAHAN PENGGUNAAN SISTEM KALA PADA PEMBELAJAR BAHASA JEPANG TINGKAT DASAR DI INDONESIA
}

\author{
Suhartini \\ Universitas Teknologi Yogyakarta \\ Email: suhartini.asrofi@gmail.com
}

\begin{abstract}
(Title: An Analysis of The Errors of Using Tenses On Basic Japanese Learners In Indonesia.) The research aims at describing the errors of using tenses in basic Japanese on learners whose first language is Bahasa Indonesia. In the process of acquiring the second language, it is possible for the first language to influence the second one because of the transfer of some fundamental elements, i.e. using tenses of the first to the second language.

The data of research are in form of Japanese language sentences that get interference of tenses formation from Indonesian language. The data were collected by observation. Contrastive method was used in analysis.

The results of the analysis show that Bahasa Indonesia tenses formation system influences the use of using tenses in basic Japanese on those who learn Japanese as a second language. The lead to the errors in using tenses in Japanese. To overcome the problem, Japanese teachers shall expose the using tenses continuously to its lerners whose first language is bahasa Indonesia.
\end{abstract}

Keywords : tenses formation, basic Japanese learners, first language, second language, and interference

\section{PENDAHULUAN}

Di era globalisasi sekarang ini, kebutuhan untuk mempelajari bahasa asing (untuk selanjutnya disebut bahasa kedua) tidak dapat dihindari. Dalam pembelajaran bahasa kedua tersebut, seringkali terjadi kontak bahasa. Merujuk pada V.Bondarko (2000:55), kontak bahasa ini biasanya terjadi pada situasi tertentu ketika dalam sebuah komunitas tertentu dua bahasa hidup berdampingan. Jika dikaitkan dalam situasi pembelajar bahasa kedua, maka bahasa pertama yang dalam tulisan ini merujuk pada bahasa Indonesia dapat disebut sebagai bahasa ibu (mother tongue)dan bahasa kedua yang merujuk pada bahasa Jepang dapat disebut sebagai bahasa resmi (official language).

Kontak bahasa ini terjadi pada saatpembelajar melakukan transfer dari kebiasaan bahasa pertama (bahasa ibu) yang telah dikuasai oleh pembelajar kepada bahasa kedua yang sedang dipelajarinya. Hal ini mengakibatkan sering tercampurya kaidah bahasa pertama ke dalam kaidah bahasa kedua yang sedang dipelajari. Dalam ilmu linguistik, peristiwa seperti ini disebut dengan istilah interferensi, yaitu kesalahan berbahasa berupa unsur bahasa sendiri yang dibawa ke dalam bahasa atau dialek lain yang dipelajari (Kridalaksana, 2009:95).

Salah satu yang sering mendapatkan interferensi dari bahasa Indonesia ke dalam bahasa Jepang adalah pada pembentukan kala. Dalam bahasa Indonesia, kala dapat diungkapkan secara leksikal melalui pewatas verba atau dalam bentuk kata keterangan waktu. Contohnya adalah untuk mengungkapkan kala yang menyatakan keakanan (future) dapat digunakan pewatas verba akan; untuk menyatakan kala lampau dapat digunakan kata keterangan waktu kemarin; dan untuk menyatakan kala mendatang dapat digunakan kata keterangan 
Izumi, Volume 5, No 2, 2016

e-ISSN: 2502-3535, p-ISSN: 2338-249X

Tersedia online di http://ejournal.undip.ac.id/index.php/izumi

waktu besok. Pengungkapan kala secara leksikal ini tidak mengubah atau mempengaruhi bentuk morfologis pada fungsi predikat bahasa Indonesia. Sebaliknya, dalam bahasa Jepang meskipun kadang-kadang sudah diungkapkan secara leksikal dalam bentuk kata keterangan waktu seperti kinoo 'kemarin' dan ashita 'besok', kala juga harus diungkapkan secara morfologis dalam fungsi predikatnya. Untuk fungsi predikat yang diisi oleh kategori verba, kala lampau ditandai dengan bentuk $\mathrm{V} \sim t a / \sim$ mashita; kala mendatang ditandai dengan bentuk $\mathrm{V} \sim r u / m a s u ;$ dan kala kini/sekarang yang ditandai dengan bentuk $\mathrm{V} \sim r u / \sim m a s u$ atau $\mathrm{V} \sim$ te iru/ te imasu. Untuk fungsi predikat yang terdiri dari adjektiva-i, maka untuk bentuk lampaunya ditandai dengan infleksi katta pada adjektiva-i.Untuk fungsi predikat yang terdiri dari adjektiva-na, maka untuk bentuk lampaunya ditandai dengan infleksi $\sim$ deshita/ datta dan bentuk non lampaunya ditandai dengan bentuk $\sim d e s u / \sim d a$. Infleksi pada adjektiva-na yang menunjukkan bentuk lampau dan non lampau tersebut sama dengan perubahan verba bantu yang berfungsi untuk menunjukkan bentuk lampau dan non lampau pada nomina.

Dengan kata lain, dalam bahasa Jepang harus ada kesesuaian antara keterangan waktu yang diungkapkan secara leksikal dengan bentuk kala yang melekat secara morfologis pada fungsi predikatnya. Sebaliknya, bahasa Indonesia tidak memiliki pemarkahan morfologis untuk kala sehingga fungsi predikatnya selalu diungkapkan dengan cara yang sama meskipun keterangan waktunya menunjukkan kala yang berbeda.

Berdasarkan hal tersebut, penelitian ini berkaitan dengan analisis kesalahan penggunaan sistem kala dalam bahasa Jepang tingkat dasar yang dilakukan oleh pembelajar bahasa Jepang tingkat dasar di Indonesia. Kalimat-kalimat bahasa Jepang diperoleh dari mahasiswa tingkat dua di program studi D3 Bahasa Jepang Universitas Teknologi Yogyakarta dalam bentuk tertulis, yaitu pada saat kegiatan sakubun (mengarang).

\section{METODE PENELITIAN}

Metode linguistik yang digunakan untuk mengumpulkan data dalam penelitian ini adalah metode simak. Metode simak dilakukan dengan cara mengumpulkan data berupa kalimat-kalimat bahasa Jepang hasil karangan pembelajar bahasa Jepang tingkat dasar dalam kegiatan perkuliahan sakubun 'mengarang'. Dalam metode simak, teknik dasar yang dilakukan berupa teknik sadap, yaitu dengan menyadap penggunaan bahasa Jepang dalam hasil karangan mahasiswa yang mendapatkan interferensi pembentukan kala dari bahasa Indonesia. Karena dalam kegiatan menyimak ini penulis tidak terlibat langsung untuk ikut menentukan pembentukan dan pemunculan calon data atau dengan kata lain hanya sebagai pemerhati saja, maka teknik lanjutan yang digunakan berupa SBLC (simak bebas libat cakap) di atas.

Setelah data terkumpul, analisis dilakukan melalui metode kontrastif. Metode kontrastif ini dilakukan dengan cara membandingkan perbedaan penggunaan sistem kala dalam bahasa Indonesia dengan sistem kala dalam bahasa Jepang sehingga menyebabkan terjadinya kesalahan penggunaan sistem kala bahasa Jepang tingkat dasar tersebut.

\section{HASIL DAN PEMBAHASAN}

Dalam proses pembelajaran bahasa kedua, dikenal adanya istilah transfer dan interferensi (Brown, 2008:109). Transfer adalah istilah umum yang menjelaskan pengalihan performa atau pengetahuan sebelumnya ke dalam pembelajaran berikutnya. Transfer positif terjadi ketika pengetahun terdahulu menunjang kegiatan pembelajaran, yaitu ketika item terdahulu diterapkan dengan tepat pada pembelajaran selanjutnya. Sebaliknya, transfer negatif terjadi ketika performa sebelumnya mengganggu performa pembelajaran 
Izumi, Volume 5, No 2, 2016

e-ISSN: 2502-3535, p-ISSN: 2338-249X

Tersedia online di http://ejournal.undip.ac.id/index.php/izumi

sesudahnya. Transfer negatif ini sering disebut dengan istilah interferensi.

Dengan kata lain, dalam pembelajaran bahasa kedua, interferensi ini terjadi karena materi-materi yang dipelajari (dikuasai) sebelumnya mencampuri materimateri berikutnya dengan cara sebuah item terdahulu dialihkan atau dikaitkan secara tidak tepat pada item yang hendak/sedang dipelajari. Dalam bahasa Jepang, interferensi ini dikenal dengan istilah bogo-kanshoo 'kesalahan karena pengaruh bahasa ibu pembelajar masing-masing' (Sutedi, 2004:190). Interferensi pembentukan kala dari bahasa Indonesia ke dalam bahasa Jepang ini penulis temukan dalam pembentukan kala pada verba, Adjektiva-i, Adjektiva-na, dan Nomina+Verba Bantu berikut ini.
1) Pembentukan Kala Pada Verba

Interferensi pembentukan kata dalam fungsi predikat berupa kala yang dibentuk dari verba ini penulis temukan pada beberapa kalimat bahasa Jepang di bawah ini yang seharusnya dituliskan dalam kala lampau (KL) $\mathrm{V} \sim t a / \sim m a s h i t a$, namun tetap dituliskan dalam bentuk kala non lampau (KNL) V ru/ masu.

Pertama, pada kalimat yang secara leksikal sudah disebutkan keterangan waktunya yang menunjukkan keterangan lampau, yaitu kinoo 'kemarin' pada kalimat (1a) berikut ini. Interferensi terjadi karena ikimasu 'pergi' seharusnya dituliskan dalam bentuk lampau, namun tetap dituliskan dalam bentuk non lampau seperti dalam bahasa Indonesia yang tidak mengenal verba bentuk lampau.

\begin{tabular}{|c|c|c|c|c|c|c|c|}
\hline (1a) & * Watashi & $w a$ & kinoo & konsaato & $e$ & $i k i$ & masu. \\
\hline & & & & & & \multicolumn{2}{|c|}{$\mathbf{P}$} \\
\hline & 'saya' & pos & 'kemarin' & 'konser' & pos & \multicolumn{2}{|c|}{ 'pergi' } \\
\hline & & & & & & & KNL \\
\hline & Saya kem & ner & ke pertunj & a konser.' & & & \\
\hline
\end{tabular}

Kalimat (1a) di atas tidak gramatikal, karena tidak ada kesesuaian antara keterangan waktu yang menunjukkan lampau, yaitu kinoo 'kemarin' dengan bentuk kala pada fungsi predikatnya tersebut, yaitu ikimasu 'pergi' (non lampau). Agar gramatikal, maka fungsi predikatnya juga harus menunjukkan bentuk lampau dengan cara merubah bentuk-masu yang melekat pada kata ikimasu tersebut menjadi -mashita, sehingga ikimasu harus dirubah menjadi ikimashita 'pergi' (lampau). Secara morfologis, ikimashita tersebut dibentuk dari akar kata kerja ik'pergi' yang mendapatkan infleksi berupa voice $-i-+$-mashita yang merupakan penanda bentuk kalimat positif lampau sopan bahasa Jepang.Dengan demikian, kalimat (1a) di atas seharusnya diungkapkan dalam kalimat (1)berikut ini.

\begin{tabular}{|c|c|c|c|c|c|c|c|}
\hline (1) & Watashi & $w a$ & kinoo & konsaato & $e$ & $i k i$ & mashita. \\
\hline & & & & & & & $\mathbf{P}$ \\
\hline & 'saya' & pos & 'kemarin' & 'konser' & pos & & pergi' \\
\hline & & & & & & & KL \\
\hline
\end{tabular}

Interferensi kala lainnya penulis ketemukan dalam kalimat (2a) berikut ini yang keterangan waktunya tidak diungkapkan secara leksikal dalam bentuk kata keterangan waktu, namun secara eksplisit ditunjukkan dari hubungan sebabakibat antara klausa 1 Sono nyuusu o kiite 'mendengar berita itu' dengan klausa 2 *bikkuri shimasu 'terkejut'. 
Izumi, Volume 5, No 2, 2016

e-ISSN: 2502-3535, p-ISSN: 2338-249X

Tersedia online di http://ejournal.undip.ac.id/index.php/izumi

\begin{tabular}{|l|c|c|c|c|c|c|c|}
\hline (2a) & * Sono & nyuusu & $o$ & $k i$ & ite, & bikkuri shi & masu. \\
\hline & & & & P1 & P2 \\
\hline & 'itu' & 'berita' & pos & 'mendengar' & 'terkejut' \\
\hline & & & & & & KNL \\
\hline & \multicolumn{7}{|l}{ 'Mendengar berita itu, aku terkejut'. } \\
\hline
\end{tabular}

Interferensi terjadi pada unsur predikat

2 pada klausa 2 (klausa akibat) yang diisi oleh unsur kata kerja *bikkuri shimasu 'terkejut' akibat hasil perbuatan pada klausa 1, yaitu sono nyuusu o kiite 'mendengar berita itu'. Dalam bahasa Indonesia, perasaan terkejut sebagai suatu akibat (sudah terjadi) diungkapkan sama saja dengan perasaan terkejut yang diharapkan terjadi seperti pada kalimat Aku harap dia akan terkejut mendengar berita itu. Sebaliknya, dalam bahasa Jepang ada pembedaan pada perasaan terkejut yang sudah terjadi 'bikkuri shimashita' dengan perasaan terkejut yang belum terjadi (diharapkan terjadi) 'bikkuri shimasu'.

Dengan demikian, kalimat (2a) di atas tidak gramatikal. Agar gramatikal, maka *bikkuri shimasu tersebut seharusnya diungkapkan dalam bentuk kalalampaumashitamenjadi bikkuri shimashita. Secara morfologis, bikkuri shimashita dibentuk dari nomina bikkuri 'kejutan' ditambah verba shimasu 'melakukan/mengerjakan' yang berfungsi mengubah kategori nomina menjadi kategori verba menjadi bikkuri shimasu 'terkejut' (non lampau). Karena menunjukkan kala lampau, maka infleksi -masu pada bikkuri shimasu tersebut seharusnya dirubah menjadi -mashita, sehingga menjadi bikkuri shimasu seharusnya dirubah menjadi bikkuri shimashita 'terkejut' seperti pada kalimat (2) berikut ini.

\begin{tabular}{|c|c|c|c|c|c|c|}
\hline (2) & Sono & пуиияи & $o$ & ite, & bikkuri shi & mashita. \\
\hline & & & & P1 & \multicolumn{2}{|c|}{ P2 } \\
\hline & 'itu' & 'berita' & pos & 'mendengar' & \multicolumn{2}{|c|}{ 'terkejut' } \\
\hline & & & & & & KL \\
\hline & 'Men & ar beri & $\mathrm{u}, \mathrm{a}$ & terkejut'. & & \\
\hline
\end{tabular}

Bentuk kalimat lainnya yang mendapatkan interferensi kala dari bahasa Indonesia adalah pada kalimat (3a) berikut yang keterangan waktunya diungkapkan secara leksikal melalui penggunaan posposisi made yang berfungsi sebagai pemarkah 15-sai 'umur 15 tahun'. Jika diamati secara gramatikal, maka posposisi made dalam kalimat tersebut dapat diartikan sejak yang menandakan bahwa pada saat tuturan terjadi pembicara telah melewati batas usia tersebut (lewat dari 15 tahun).

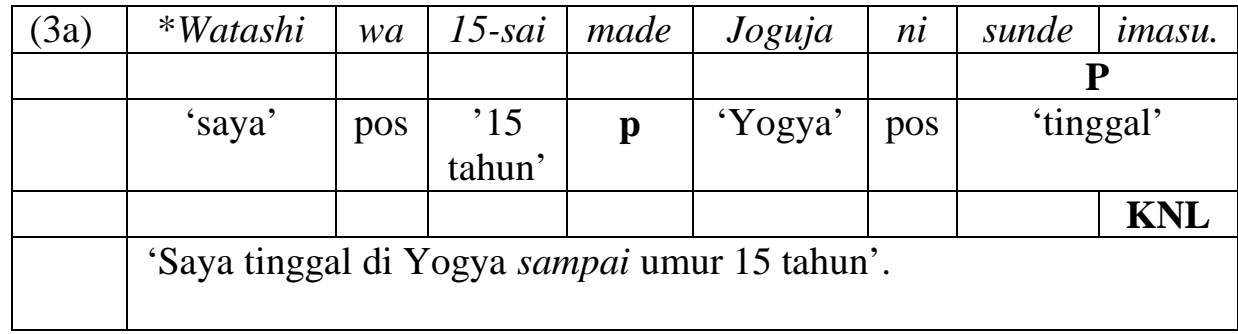

Interferensi terjadi pada penggunaan posposisi made yang seharusnya memberi konsekuensi terhadap bentuk kala lampau pada fungsi predikat sundeiru 'tinggal', namun pembelajar tetap menuliskannya dalam bentuk kala sedang sundeimasu 'tinggal' (bentuk non lampau). Pembelajar tidak menangkap konsekuensi penggunaan 
Izumi, Volume 5, No 2, 2016

e-ISSN: 2502-3535, p-ISSN: 2338-249X

Tersedia online di http://ejournal.undip.ac.id/index.php/izumi

posposisi made tersebut dan menyamakannya dengan penggunaan preposisi sampai dalam bahasa Indonesia yang tidak memberi konsekuensi penggunaan kala lampau secara morfologis pada fungsi predikatnya. Demikian, agar

gramatikal maka fungsi predikat sunde imasu 'tinggal' tersebut seharusnya diungkapkan dalam bentuk lampau -mashita menjadi sunde imashita seperti dalam kalimat (3) berikut ini

\begin{tabular}{|c|c|c|c|c|c|c|c|c|}
\hline (3) & Watashi & $w a$ & 15-sai & made & Joguja & $n i$ & sunde $i$ & mashita. \\
\hline & & & & & & & \multicolumn{2}{|c|}{$\mathbf{P}$} \\
\hline & 'saya' & pos & '15 tahun' & pos & 'Yogya' & pos & \multicolumn{2}{|c|}{ 'tinggal' } \\
\hline & & & & & & & & KL \\
\hline & 'Saya $t i$ & $u$ & Yogya $s c$ & ii un & 15 tahu & & & \\
\hline
\end{tabular}

\begin{tabular}{|c|c|c|c|c|c|}
\hline (4a) & *Yuube & isogashi & $i$ & desu & $k a$. \\
\hline & & \multicolumn{4}{|c|}{$\mathbf{P}$} \\
\hline & 'semalam' & \multicolumn{2}{|c|}{ 'sibuk' } & \multicolumn{2}{|c|}{ 'apakah' } \\
\hline & & & KNL & VB & $\mathrm{p}$ \\
\hline & \multicolumn{5}{|c|}{ 'Apakah semalam sibuk?' } \\
\hline
\end{tabular}

Interferensi pada kalimat (4a) di atas terjadi pada adjektiva-i dalam fungsi predikatnya, yaitu isogashii yang seharusnya menunjukkan kesesuaian dengan keterangan waktunya yang menunjukkan kala lampau, yaitu kinoo 'kemarin'. Tidak adanya kesesuaian antara bentuk adjektiva dengan keterangan waktu tersebut terpengaruh oleh pola pikir terjemahan bahasa Indonesia yang tidak mengenal bentuk kala pada fungsi predikatnya.

Agar gramatikal dalam bahasa Jepang, maka adjektiva-i dalam fungsi predikatnya, yaitu isogashii tersebut harus menunjukkan kesesuaian dengan keterangan waktunya yang menunjukkan kala lampau, yaitu kinoo 'kemarin'. Untuk adjektiva-i yang berakhiran dengan gobi-i, jika keterangan waktunya menunjukkan waktu lampau positif seperti di atas, maka gobi $-i$ harus dirubah dengan gobi-katta.

Dengan demikian, isogashi-i 'sibuk' pada kalimat (4a) di atas seharusnya ditulis menjadi isogashikattaseperti dalam kalimat (4) di bawah ini.

\begin{tabular}{|c|c|c|c|c|c|}
\hline (4) & Yuube & isogashi & katta & desu & $k a$. \\
\hline & & \multicolumn{4}{|c|}{$\mathbf{P}$} \\
\hline & 'semalam' & \multicolumn{2}{|c|}{ 'sibuk' } & \multicolumn{2}{|c|}{ 'apakah' } \\
\hline & & & KL & VB & $\mathrm{p}$ \\
\hline & \multicolumn{5}{|c|}{ 'Apakah semalam sibuk?' } \\
\hline
\end{tabular}

2) Pembentukan Kala Pada Adjektiva-Na

Untuk interferensi pembentukan kala pada akar kata adjektiva-na penulis ketemukan dalam data kalimat (5a) berikut ini.

\begin{tabular}{|l|l|l|l|l|c|}
\hline (5a) & *Kinoo & Marioboro & wa & totemo & nigiyaka desu. \\
\hline & & & & \multicolumn{3}{|c|}{ P } \\
\hline & 'kemarin' & 'Malioboro' & pos & 'sangat' & 'ramai' \\
\hline \multicolumn{7}{|l}{} \\
\hline
\end{tabular}


Izumi, Volume 5, No 2, 2016

e-ISSN: 2502-3535, p-ISSN: 2338-249X

Tersedia online di http://ejournal.undip.ac.id/index.php/izumi

Dalam kalimat (5a) di atas, interferensi terjadi pada predikat *totemo nigiyaka desu 'ramai' yang seharusnya bentuk morfologisnya disesuaikan dengan kata keterangan waktu yang ditunjukkan, yaitu kinoo 'kemarin' namun diungkapkan dengan pola pikir pembentukan dalam bahasa Indonesia yang tidak mengenal perbedaan bentuk lampau dan non lampau pada fungsi predikatnya.

Fungsi predikat totemonigiyaka desu 'ramai' dalam kalimat di atas dibentuk dari kata totemo yang masuk kategori fukushi atau kata keterangan ditambah akar kata (gokan) adjektiva-na, yaitu nigiyaka dan infleksi (gobi) desu yang sekaligus menandakan bentuk kalimat non lampau positif sopan. Dengan demikian, ketidakgramatikalan dalam kalimat tersebut terletak pada infleksi (gobi) desu yang sekaligus menandakan bentukkalimat non lampau positif sopan.

Agar gramatikal, infleksi desu pada fungsi predikat kalimat (5a) di atas seharusnya diganti dengan infleksi deshita yang menyatakan bentuk lampau sehingga ungkapan *totemo nigiyaka desu seharusnya dirubah menjadi totemo nigiyaka deshita 'ramai' seperti dalam kalimat (5) berikut ini.

\begin{tabular}{|l|l|l|l|l|c|}
\hline (5) & Kinoo & Marioboro & wa & totemo & nigiyaka deshita. \\
\hline & & & & \multicolumn{3}{|c|}{$\mathbf{P}$} \\
\hline & 'kemarin' & 'Malioboro' & pos & 'sangat' & 'ramai' \\
\hline & \multicolumn{2}{|c|}{ 'Kemarin Malioboro sangat ramai'. } \\
\hline
\end{tabular}

3) Pembentukan Kala Pada Nomina+Verba Bantu

Seringkali interferensi pembentukan kala ini juga terjadi pada fungsi predikat bahasa Jepang yang dibentuk dari kategori nomina + verba bantu. Berbeda dengan keberadaan verba bantu yang mengikuti adjektiva-i dalam kalimat (4) di atas yang keberadaannya dalam fungsi predikat tidak bersifat wajib, keberadaan verba bantu yang mengikuti nomina ini bersifat wajib. Hal itu didasari oleh sifat nomina tidak dapat mengalami perubahan bentuk, sehingga untuk menyatakan bentuk lampau dan non lampau harus dibantu dengan verba bantu yang dapat menunjukkan perubahan bentuk lampau dan non lampau.

Penulis menemukan interferensi gramatikal bahasa Indonesia dalam fungsi predikat yang dibentuk oleh kategori nomina yang menyatakan hari, yaitu suiyoobi 'haru Rabu' yang dikuti oleh verba bantu desu pada kalimat (6a) berikut.

\begin{tabular}{|c|c|c|c|c|}
\hline (6a) & * Ototoi & $w a$ & suiyoobi & desu. \\
\hline & & & \multicolumn{2}{|l|}{$\mathbf{P}$} \\
\hline & 'kemarin lusa' & pos & 'hari Rabu' & KNL \\
\hline & \multicolumn{4}{|c|}{ 'Kemarin lusa adalah hari Rabu' } \\
\hline
\end{tabular}

Pada kalimat (6a) di atas, interferensi terjadi pada pengungkapan verba bantu berupa desu yang seharusnya diungkapkan dalam bentuk lampau deshita karena adanya kata keterangan waktu ototo $i$ 'kemarin lusa', namun pembelajar tetap mengungkapkannya dalam bentuk non lampau -desu seperti konsep pemikiran yang ada dalam pembentukan predikat bahasa Indonesia yang tidak mengenal bentuk kala.

Agar gramatikal, verba bantu-desu dalam kalimat tersebut seharusnya diungkapkan dalam bentuk lampau -deshita seperti dalam kalimat (6) berikut. 
Izumi, Volume 5, No 2, 2016

e-ISSN: 2502-3535, p-ISSN: 2338-249X

Tersedia online di http://ejournal.undip.ac.id/index.php/izumi

\begin{tabular}{|l|l|l|l|l|}
\hline (6) & Ototoi & $w a$ & \multicolumn{1}{c|}{ suiyoobi } & deshita. \\
\hline & & & \multicolumn{2}{|c|}{ P } \\
\hline & \multicolumn{1}{|c|}{ 'kemarin lusa' } & pos & 'hari Rabu' & KL \\
\hline \multicolumn{4}{|l}{ 'Kemarin lusa adalah hari Rabu' } \\
\hline
\end{tabular}

\section{SIMPULAN}

Interferensi pembentukan kala dari bahasa Indonesia ke dalam kalimat-kalimat bahasa Jepang sering terjadi pada pembentukan kala pada verba, adjektiva-i, adjektiva-na, dan kata bantu yang mengikuti kata benda. Interferensi ini terjadi karena pembelajar bahasa Jepang tingkat dasar secara tidak sadar seringkali mentransfer pembentukan kala dalam bahasa Indonesia yang cukup diungkapkan dalam bentuk leksikal saja ke dalam kalimat-kalimat bahasa Jepang. Untuk mengatasinya, pengajar secara terus-menerus perlu melakukan pendedahan agar pembelajar bahasa Jepang akhirnya tidak lagi mencampuradukkan pola pembentukan kala dari bahasa Indonesia ke dalam bahasa Jepang.

\section{DAFTAR PUSTAKA}

Brown, H.Douglas. 2008. Prinsip Pembelajaran Bahasa. Penerjemah : Noor Cholis dan Yusi Avianto Pareanom. Jakarta : Kedutaan Besar Amerika Serikat.

Kridalaksana, Harimurti. 2009. Kamus Linguistik. Edisi keempat cetakan kedua (dengan koreksi).Jakarta : Gramedia.
Sutedi, Dedi. 2004. Dasar-dasar Linguistik Bahasa Jepang. Bandung : Humaniora Utama Press.

V. Bondarko, Liya. 2000. Language Contacts: Phonetic Aspects. Source: Studies in Slavic and General Linguistics, Vol. 28, Languages in Contact (2000), pp.55-65. Published by: Brill.Stable URL: http://www.jstor.org/stable/40997151. 